\title{
Eutrophication and Phosphorous accumulation in sediments of Karlskärsviken, bay in Lake Mälaren
}

\author{
Gull Olli \\ Department of Physical Geography and Quaternary Geology, Stockholm University, SE-10691, Stockholm, \\ Sweden \\ Corresponding author: E-mail: gull.olli@,natgeo.su.se
}

\section{Supporting information:}

1. I have measured the current BSi content in the uppermost sediments and the current $\mathrm{P}$ content in the respective water column at 12 locations in surrounding bays. I got a consistent ratio TP BSi-1 for all locations of about 0.68 -3. Then I multiplied all the core sediment $\mathrm{BSi}$ values with $0.68-3$ obtaining a rough estimate of past $\mathrm{P}$ content, $\mathrm{BSi}-\mathrm{P}$, in the water column. All earlier such transfer methods cited and discussed on pages 2 and 5 (Round, 1981, Stoermer, 1984, Schelske et al., 1983 and 1986, Anderson et al., 1993, Bennion et al., 1996 and Renberg, 1999; ter Braak \& van Dam, 1989, Anderson et al., 1993, Bennion et al., 1996 and Bradshaw \& Anderson, 2001) give similarly approximate values.

2. Sediment dating for medieval times was based on the presence of brackish-and freshwater diatoms and for modern times on the number of fly-ash particles from fossil fuel (SCP). The preparation of diatom slides for analysis followed methods described by Battarbee (1986). The transition from brackish to freshwater was elongated by various 
transgression and regression phases, which have been recognized in other studies ( $\AA$ se, 1980, Miller \& Robertsson, 1982, Ambrosiani, 1981, Miller \& Hedin, 1988) and also here in Karlskärsviken. The content of the caesium isotope Cs-137 was established in the core 3. The history of SCP presence in sediments is established by Griffin and Goldberg (1975, 1979), Wik (1992), Odgaard (1993), Rose et al., (1990, 1995, 1999, 2001), Bindler et al. (2002) and Renberg et al. (2001), on which the dating of the modern sediments in Karlskärsviken is based. For SCP counting the sediment samples were prepared according to Rose (2001). The increase and decrease of lead and SCP pollutants in modern times are expected to coincide, if there is no local polluter (Wik, 1992 and Bindler et al., 2002). The knowledge of the local activities during the second half of the twentieth century has also been used for chronological control.

3 Sediment mass accumulation rates from Olli (2007)

$\begin{array}{lrrrrr}\begin{array}{l}\text { Sediment mass accumulation rate } \mathrm{g} \mathrm{DM} / \mathrm{cm}^{2} / \mathrm{yr} \\ \text { Year/core }\end{array} & 1 & 3 & 4 & 5 \\ & 2000 & & 0,06 & 0,19 & 0,23 \\ 1973 & 0,06 & 0,07 & 0,11 & 0,22 \\ 1950 & 0,04 & 0,04 & 0,05 & 0,1 \\ 1900 & 0,04 & 0,04 & 0,05 & 0,09 \\ 1500 & 0,03 & & 0,05 & 0,08 \\ 1200 & 0,03 & & 0,05 & 0,06\end{array}$

\begin{tabular}{lr}
\multicolumn{2}{c}{ Mean value of mg B Si/cm2/yr. } \\
2000 & 4,4 \\
1973 & 4,4 \\
1945 & 1,9 \\
1850 & 1,5 \\
1550 & 1,4 \\
1200 & 1,2
\end{tabular}

